\title{
Study on hybrid biorack constructed wetland
}

\author{
Guru Munavalli $i^{*}$, Pratap Sonavane ${ }^{2}$, Sagar Wandare ${ }^{3}$, Kusum Biradar $^{4}$, and Nikhil Aswale \\ ${ }^{1-5}$ Department of Civil Engg., Walchand College of Engineering, Sangli, Maharashtra, India
}

\begin{abstract}
Decentralized Wastewater Treatment Systems (DWTS) based on natural mechanisms of purification are appropriate for Indian conditions. Biorack constructed wetland are recent developments in the domestic wastewater treatment. In the present study the concept of biorack wetland is extended to Hybrid Biorack Constructed Wetland (HBCW) in which bioracks are supplemented by brickbat as support medium for wetland vegetation. Three separate HBCW reactors were developed with Typha angustifolia, Canna indica and dual-species (Typha angustifolia and Canna indica). Batch studies were carried out on these reactors for secondary treatment of domestic wastewater. COD removal was determined for feed wastewater strength of 100 to $200 \mathrm{mg} \mathrm{COD/L}$ by these developed reactors. The growth of vegetation was also monitored. Typha angustifolia and Canna indica were found to be an appropriate combination as dualspecies. The COD removal by dual-species is 5 to $10 \%$ greater than mono-species under similar conditions of feed and support medium. HBCW is efficient to an extent of 65 to $75 \%$ for COD removal. This is preliminary study conducted on HBCW. Further studies on pilot/field scale will provide better insight to assess its suitability as an alternative biological treatment.
\end{abstract}

\section{Introduction}

Domestic wastewater is composed of greywater and blackwater. The generation of this type of wastewater is increasing with time. The disposal without treatment is problematic as it leads to contamination of groundwater and surface water. The treatment facilities wherever available are either centralized or decentralized. The centralized treatment facilities are normally provided and operated by municipal authorities. Such facilities have pre-requisite of collection/sewerage system. The fund required to build and operate these systems is large. It is a fact that the larger systems have more operational difficulties and thereby necessitating more mechanization. Further, the application of technologies based on natural mechanisms of purification may not be feasible for large scale application. Decentralized Wastewater Treatment System (DWTS) may be an alternative to centralized treatment systems for on-site treatment of domestic wastewater. The proven benefits of DWTS include cost effective, incorporation of natural mechanisms of purification in treatment system, reduce load on municipal treatment systems, better control over operation and maintenance, and scope for recycle and reuse. Further, individual households, isolated domestic establishments, small housing townships, educational organization, and commercial establishments can be provided with DWTS. The treatment in DWTS may be aerobic, anaerobic, or combination of these. A typical DWTS may have either anaerobic treatment in the form of baffled reactor/filter followed by primary and secondary Constructed Wetland (CW) or aerobic moving bed bioreactor. In Indian context, first option is more feasible provided space is available due to the use of natural mechanisms in treatment line. However, there are studies conducted on $\mathrm{CW}$ and possible modifications to conventionally developed $\mathrm{CW}$. Biorack CW (BRCW) are one of such modifications. Conventional Bio-Rack Wetland System (CBRWS) is one of the latest configuration in wetland technologies that was developed by [10] to overcome the drawbacks of CW. CBRWS is the grid arrangement of racks having perforations for liquid transport in which plants are placed in the absence of any other supporting media. This is a robust biological practice that can be applied to an efficient and reliable elimination of pollutants, even under unfavorable influent conditions stressed by high total dissolved solids and heavy metal $[7,10,11]$. The reported studies on CBRWS include $[6,10,11]$ for domestic wastewater treatment and [13] for treatment of low polluted river water. All these studies have demonstrated the potential use of CBRWS in wastewater treatment. Further, [9] modified CBRWS by using non- perforated bioracks and inducing plugflow pattern into the system and demonstrated

*Corresponding author: guru.munvalli@walchandsangli.ac.in 
enhancement in the performance of $\mathrm{BRCW}$ for the removal of Organic Carbon. The primary component of BRCW is system of pipes and cost of the system is governed by this component. [9] tried to minimize the cost of BRCW by using discarded plastic package drinking water $(1 \mathrm{~L})$ bottles. The development of root matrix of wetland plants plays a significant role in the performance of BRCW. Vertical spread of root matrix is more encouraged in BRCW. It is hypothysed that the combination of vertical and lateral spread of root matrix enhances the treatment potential of BRCW. In the present study, the following contributions to existing knowledge on BRCW are addressed;

1. The brickbats are used as support media for vegetation and thus replacing the bioracks partially. This modification reduces the cost of system and provides scope of vertical and lateral development of root matrix.

2. The multi-species vegetation is used in bioracks and brickbat medium. This enables proper root matrix in the system. The developed system is referred as Hybrid Biorack Constructed Wetland (HBCW) in the present study.

\section{Materials and methods}

\subsection{Source of wastewater}

The settled domestic wastewater generated from campus of Walchand College of Engineering, Sangli (Maharashtra, India) was collected from primary settling tank and used as influent to $\mathrm{HBCW}$. The contributing sources to this wastewater from college campus included food establishments (mess and canteen), greywater and septic tank effluent from residences, and hostels.

\subsection{Experimental HBCW}

Fig. 1 shows schematic sketch and photographic view of $\mathrm{HBCW}$. The developed systems include HBCW with Canna indica (Reactor 1), HBCW with Typha angustifolia (Reactor 2) and HBCW (Multispecies with Canna indica and Typha angustifolia). Each reactor of $\mathrm{HBCW}$ was made up of seven $80 \mathrm{~mm}$ diameter $0.70 \mathrm{~m}$ deep corrugated plastic pipe (as bioracks) surrounded by brickbats medium in $80 \mathrm{~L}$ plastic tank of $0.70 \mathrm{~m}$ diameter. The wetland plants were vegetated in the respective reactors as specified above. Canna indica and Typha angustifolia were collected from a nearby stream and acclimatized before initial plantation in $\mathrm{HBCW}$. The size of brickbats used was $20 \mathrm{~mm}$ to $40 \mathrm{~mm}$ and measured porosity was $45 \%$ of brickbat medium. The locally available Canna indica and Typha angustifolia were chosen as these were well proven as wetland vegetation [1, 2, 4, 5, 8, 14] surviving, growing and multiplying in saturated conditions and capable of releasing the dissolved oxygen through roots. Initially, 10 plants each were vegetated in reactors 1 and 2 , whereas reactor 3 has 5 plants each of Canna indica and Typha angustifolia. The average initial depth of roots of each plant was $50 \mathrm{~mm}$. The lateral spread was also measured and was $30 \mathrm{~mm}$.

\subsection{Operation of HBCW and Experimental Procedure}

The systems were operated for performance evaluation study after development of roots. Then, all systems were subjected to batch mode of operation for $30 \mathrm{~d}$. Hydraulic Retention Time of $24 \mathrm{~h}$ was used in the study for all systems for a week and systems were monitored by sampling and analyzing influent and effluent for every cycle of applied HRT. The experiments were conducted on all three systems to assess their performance for the removal of Chemical Oxygen Demand (COD). The samples were analyzed for COD following procedure of APHA [3].
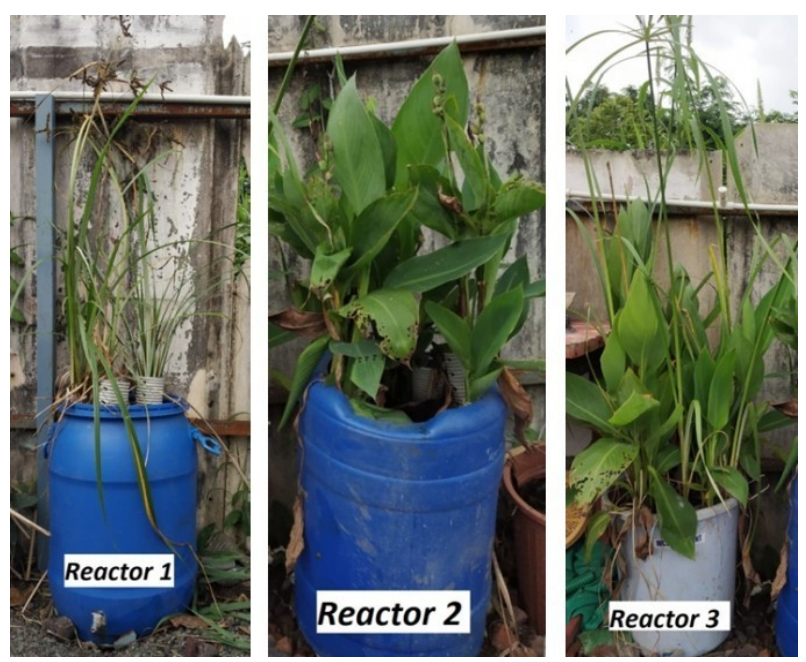

Fig. 1 Photographic view of $\mathrm{HBCW}$ a) reactor 1 ; b) reactor 2; and c) reactor 3

\section{Results and discussions}

\subsection{Wastewater Characteristics}

The characteristics of influent wastewater to $\mathrm{HBCW}$ were analyzed to check its suitability for the biological treatment. The characteristics are summarized in Table 1. It can be seen that the $\mathrm{BOD}_{3} / \mathrm{COD}$ ratio of wastewater is in the range of 0.52 to 0.63 indicating amenability of settled wastewater for biological treatment.

\subsection{COD Removal by HBCW}

Fig. 2 shows the influent COD, effluent COD and removal of COD by HBCW system planted with Typha angustifolia, Canna indica and Dual-species (Typha and Canna together). The comparative performance is shown for the reactors fed with COD of influent settled 
wastewater in the range 100 to $250 \mathrm{mg} / \mathrm{L}$. The results show that the removal efficiency is higher in HBCW reactor vegetated with Dual-species.

Table 1. Characteristics of influent wastewater

\begin{tabular}{|c|c|c|c|c|}
\hline Parameter & $\mathrm{pH}$ & $\mathrm{TSS}(\mathrm{mg} / \mathrm{L})$ & $\begin{array}{c}\mathrm{COD} \\
(\mathrm{mg} / \mathrm{L})\end{array}$ & $\begin{array}{c}\mathrm{BOD}_{3} \\
27^{\circ} \mathrm{C} \\
(\mathrm{mg} / \mathrm{L})\end{array}$ \\
\hline $\begin{array}{c}\text { Settled } \\
\text { wastewater } \\
\text { (Influent) }\end{array}$ & $\begin{array}{c}7.05 \\
\pm\end{array}$ & $138 \pm 33$ & $102 \pm 50$ & $65 \pm 14$ \\
\hline
\end{tabular}
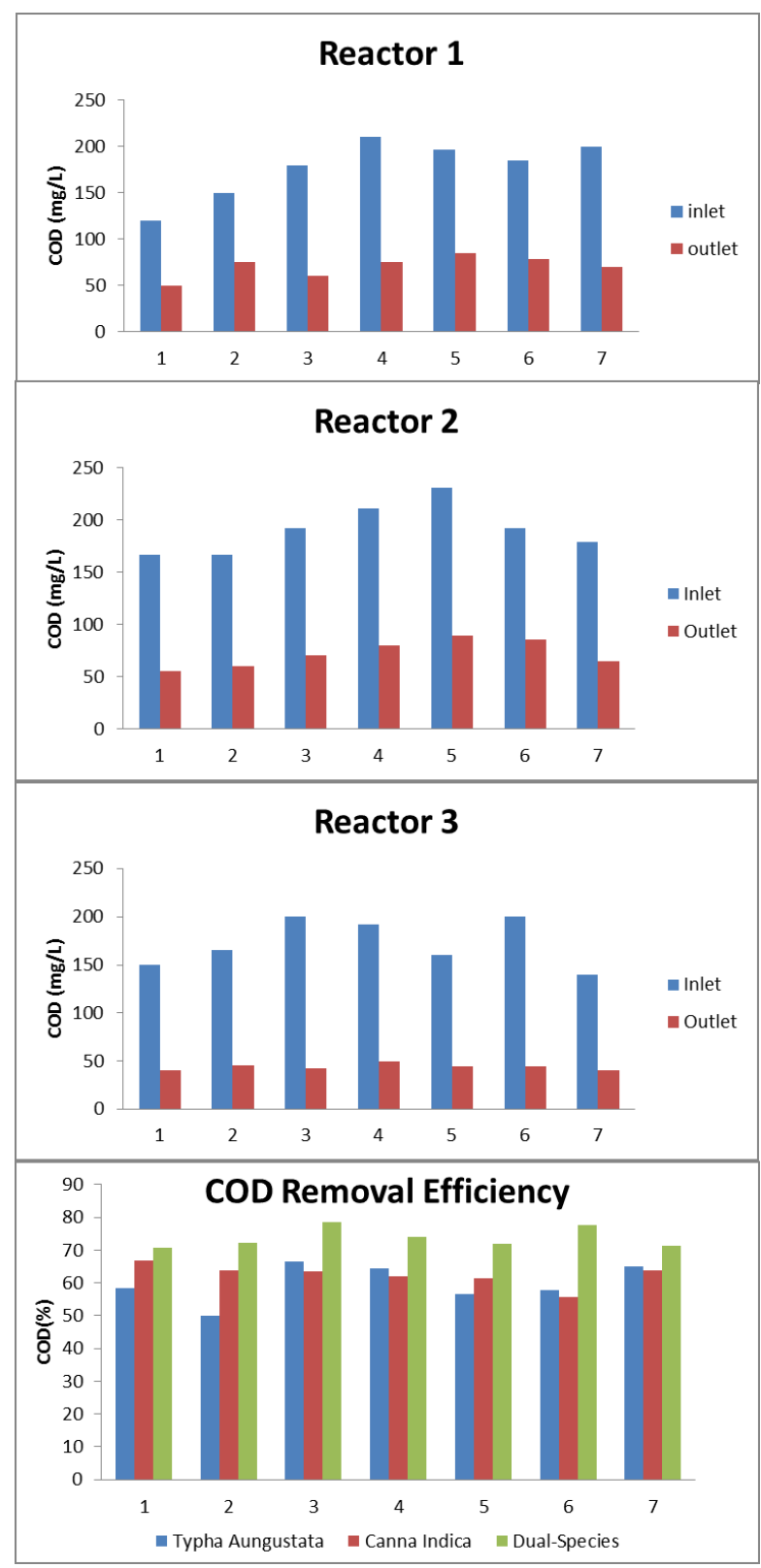

Fig. 2 COD removal by HBCW systems

The comparison of the relative performance of Canna indica and Typha angustifolia indicates both are effective. The average percent removal for both reactors
1 and 2 is $55 \%$ to $65 \%$. The removal efficiency in reactor 3 is significantly higher that of reactors 1 and 2 the same range of influent COD. These results are suggestive of the mixed type of vegetation enhances the efficiency as all the three reactors have brick bats as the support media. The combination of shallow and deep roots developed into root matrix enhances the removal. The reactor 3 with dual-species consistently has shown better removal (65 to $75 \%)$. In order to validate the effect dualspecies these results were correlated with growth of vegetation and discussed in the following section.
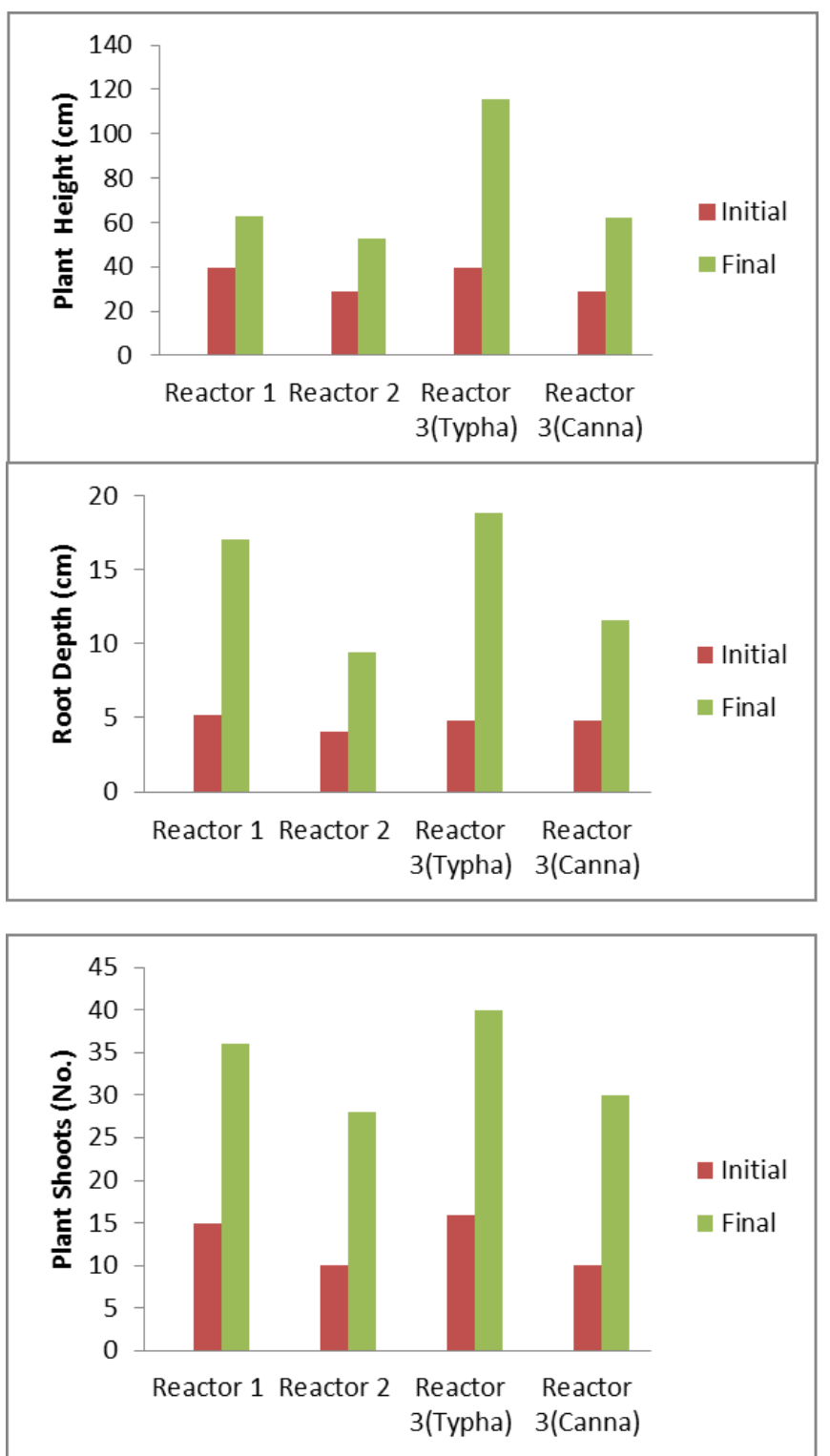

Fig. 3 Quantitative measurement of vegetation growth

\subsection{Vegetation growth in HBCW systems}

The growth of wetland vegetation in all the three reactors was monitored for a period of 30 days. The height of plants, number of shoots, depth of roots and spread of roots laterally were observed and recorded as a part of monitoring. The photographic view of vegetation growth in sample bioracks taken from respective reactors 
is shown in Fig. 4. It can be seen from the figure that bioracks support the wetland plants individually and combined/as a dual species. The roots in bioracks spread both vertically and laterally. The lateral spread of roots is evident as roots emerging through the perforations of biorack are clearly visible. The individual root matrix is also well developed.

Fig. 3 shows the quantitative measurement of vegetation growth in terms of height, root depth, root spread and number of shoots. The growth of both these plants in terms of the stated parameters is significant considering the shorter period of monitoring/study. The vegetations were well grown in brickbat medium as well as in bioracks. The average root depth of Typha angustifolia (in reactor 1) and Canna indica (in reactor 2) was observed to be $175 \mathrm{~mm}$ and $100 \mathrm{~mm}$ respectively in reactors 1 and 2 after 30 days. The root growth for both plants was 2 to 4 times the initial depth. Interestingly, the corresponding the average root depth of these plants was $200 \mathrm{~mm}$ and $125 \mathrm{~mm}$ respectively in reactor 3 . This indicates that there is no interference in the relative growth of these plants. The combination of shorter and longer roots provided by dual- species has resulted in dense matrix of roots. The matrix was so dense that root system in bioracks of reactor 3 could not be pulled out. This extra grip provided by the developed roots in dualspecies bioracks might be the reason for extra root depth of plants. The effect of development of dense matrix of roots is evident in enhancement of COD removal efficiency in reactor 3 compared to other two reactors (Fig. 2). The growth rate of plants with reference height was also significant for both the plants. The growth of Typha angustifolia is relatively more than Canna indica as mono-species and in dual-species. Its growth is more in dual-species (reactor 3). The lateral spread is to an extent of $50 \%$ more than the corresponding initial values. The spread of Typha angustifolia in reactor 3 is higher. All these results demonstrate that i) Typha angustifolia and Canna indica are suitable species for domestic wastewater treatment; ii) the combination of these two species is appropriate; and iii) dual-species $\mathrm{HBCW}$ is an alternative to CBRWS.

\section{Conclusions}

The present was carried out to assess the potential of $\mathrm{HBCW}$ in treating domestic wastewater. COD removal was primarily studied on three reactors planted with mono-species and dual-species in bioracks and brickbat medium. The relative growth of individual plants is higher in reactor with dual-species. The use of dualspecies (Typha angustifolia and Canna indica) was found to be more effective than mono-species systems in COD removal by 5 to $10 \%$. The overall COD removal that can be achieved by dual-species HBCW is 65 to $75 \%$ for HRT of $24 \mathrm{~h}$. HBCW has a potential to be an alternative to existing biological treatment for domestic wastewater.
The present study is a part of research project sanctioned by Department of Science and Technology DST) under Water Treatment Initiative (WTI) programme. The authors sincerely acknowledge and thank DST for providing financial support to undertake this study.

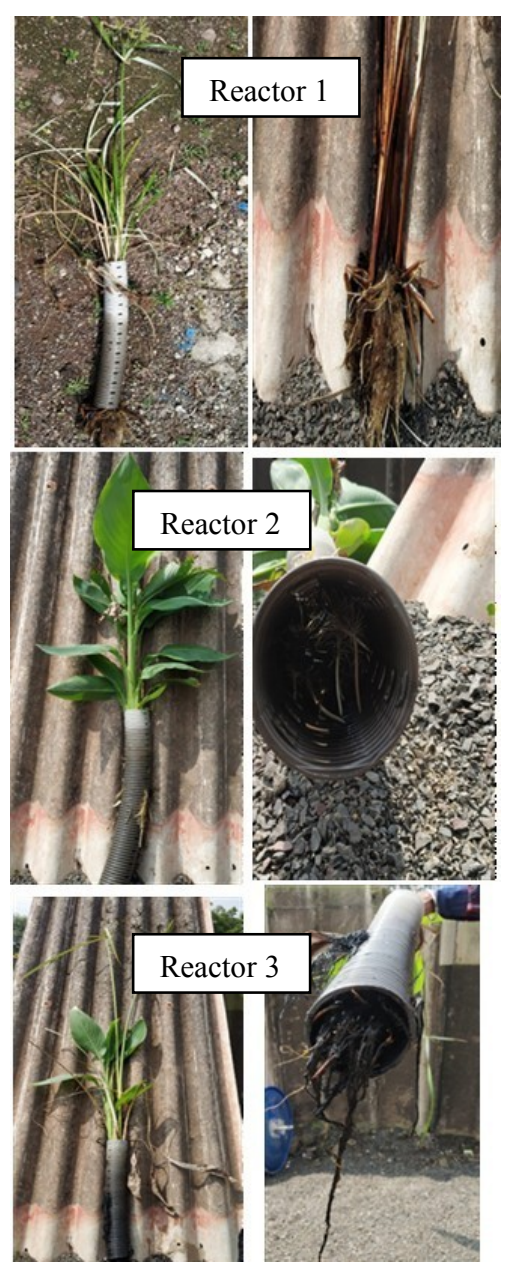

Fig. 4 Photographic view of vegetation growth in bioracks of reactor 1,2 , and 3

\section{References}

1. S. Abou-Elela and M. Hellal, Ecol Engg, 47, 209-213, (2012)

2. S. Abou-Elela, G. Golinelli, A. El-Tabl and M. Hellal, Water Sci \& Tech, Vol. 69 (1), 38-47, (2014)

3. APHA, Standard Methods for the Examination of Water and Wastewater, American Water Works Association, Water Environment Federation (2012)

4. L. Cui, Y. Ouyang, Q Lou., F Yang., Y. Chen, W. Zhu and S. Luo, Ecol Engg, 36, 1083-1088 (2010)

5. D. Ghosh and B. Gopal, Ecol Engg, 36, 10441051 (2010) 
6. S. Jamshidi, A. Akbarzadeh, K. Woo and A. Valipour, J. of Env Health Sci \& Engg, 12, 1-12 (2014)

7. L. Marchand, F. Nsanganwimana, N. Oustriere, Z. Grebenshchykova, K. Lizama-Allende, M. Mench, Ecol Engg, 64, 291-300 (2014)

8. Y. Patil and G. Munavalli, Ecol Engg, 95, 492500 (2016)

9. S. Sathe and G. Munavalli, J. of Water Process Engg, 28, 240-249 (2019)

10. A. Valipour, V. Raman and V. Ghole, Ecol Engg, 35, 1797-1803 (2009)

11. A. Valipour, V. Raman and V. Ghole, J. of Env Sci and Engg, 53(3), 281-288 (2011)

12. J. Vyazmal, Water, 2, 530-549 (2010)

13. J. Wang, L. Zhang, S. Lu, X. Jin and S. Gan, J. of Env Sci. 24 (6), 1006-1013 (2012)

14. A. Yadav, R. Abbassi, N. Kumar, S. Satya, T. Sreekrishnan and B. Mishra, Chem Engg J., 211, 501-507 (2012) 